\title{
Effect of temperature on neuromuscular transmission in the Eaton-Lambert syndrome
}

\author{
C. D. W A R D A N D N M. F. MURRA Y \\ From the Department of Neurological Science, Royal Free Hospital, and Department of Clinical \\ Neurophysiology, National Hospital for Nervous Diseases, London
}

SUMMARY A patient with the Eaton-Lambert syndrome is described in whom no associated condition was discovered. There was clinical and electrical evidence that the defect in neuromuscular transmission became more severe as local temperature was raised.

The myasthenic syndrome of Eaton and Lambert is caused by a reduction in the number of acetylcholine quanta released at the neuromuscular junction (Elmqvist and Lambert, 1968), and is frequently but by no means always associated with a neoplasm (Brown and Johns, 1974). In the patient described, in whom no associated condition was discovered, the defect in neuromuscular transmission was influenced by local temperature. This finding has not previously been reported in the Eaton Lambert syndrome.

\section{Case report}

A 54 year old man was admitted to hospital in January 1978. Eighteen months earlier he had first noticed weakness and mild discomfort in the legs. Weakness progressed so that within four months he was no longer able to work as a ship's engineer. Deterioration in the legs was gradual from that time but there was in addition mild weakness of the arms. He had noticed that the weakness was considerably worsened by a hot bath or in sunny weather. Shortly before admission he had complained of tiring of the eyes and mild slurring of speech but there were no more definite bulbar symptoms and no sensory disturbances. His general health was good, and he had not smoked for 12 years.

On examination, abnormalities were confined to the neuromuscular system. There was mild weakness of neck flexion but no other cranial nerve abnormality. He had minimal weakness of upper limb muscles and more pronounced weakness of

Address for reprint requests: Dr C. D. Ward, Department of Neurological Science, Royal Free Hospital, Pond Street, Hampstead, London NW3 2QG.

Accepted 8 September 1978 the trunk and of the proximal lower limb muscles, without wasting or fasciculation. He was unable to sit up from the supine position, and had a slow, somewhat waddling gait. Tendon reflexes were all either depressed or absent but could easily be elicited after 10 seconds of voluntary contraction of the muscle. Plantar reflexes were flexor. Sensation was normal.

Electrophysiological investigation showed the typical features of the Eaton-Lambert syndrome. Surface recording from the right abductor digiti minimi muscle (ADM) showed the resting compound muscle action potential to be grossly reduced in amplitude, being $500 \mu \mathrm{V}$ or less peak to peak. At all frequencies of repetitive stimulation there was an initial decrement in the amplitude of the resting muscle action potential. This was followed by no recovery at stimulus frequencies of $1-5 / \mathrm{s}$; by recovery, often with subsequent increment, at 10/s; and by an increment of $200-1500 \%$ of resting values at higher (15-50/s) frequencies of stimulation. Stimulation after 10 seconds of maximum voluntary contraction of ADM resulted in action potentials of up to $5 \mathrm{mV}$. The right ulnar motor nerve conduction velocity in the forearm was $56 \mathrm{~m} / \mathrm{s}$; the right median and ulnar sensory nerve action potentials (finger to wrist) were 7.5 $\mu \mathrm{V}$ and $6.0 \mu \mathrm{V}$ respectively. Electromyography of the right vastus medialis showed a "myopathic" pattern, with no spontaneous activity but many brief spiky motor unit potentials of small amplitude in a mildly reduced interference pattern.

Results of other investigations were normal, including full blood count, sedimentation rate, chest radiography, bronchoscopy, sputum cytology, serum urea, electrolytes including calcium and magnesium, thyroid, and liver function tests. After the patient's report that warm conditions made 
him weaker, further electrophysiological studies were carried out.

\section{Methods}

An active recording electrode was placed in a constant position over the belly of ADM, and an indifferent electrode was placed $40 \mathrm{~mm}$ distal to this point, over the tendon. The hand was immobilised in a splint and skin temperature was measured with a shielded thermistor probe on the thenar eminence. Local cooling was achieved by surrounding the wrist and hand with ice-filled bags, and an infrared lamp was used for warming.

Trains of stimuli of three seconds duration were delivered to the ulnar nerve at the wrist at $2 / \mathrm{s}$ and at $10 / \mathrm{s}$, each after at least five minutes relaxation, and at $2 / \mathrm{s}$ immediately after 10 seconds maximal voluntary contraction of ADM. This procedure was carried out on several occasions at room temperature, after warming, and finally after cooling (skin temperatures respectively $33-35^{\circ} \mathrm{C}, 38-40^{\circ} \mathrm{C}$, and $15-20^{\circ} \mathrm{C}$ ). Two healthy subjects were used as controls.

\section{Results}

ACTION POTENTIAL IN RESTING MUSCLE

Over the temperature range $16-40^{\circ} \mathrm{C}$ there was a progressive decline in the compound muscle action

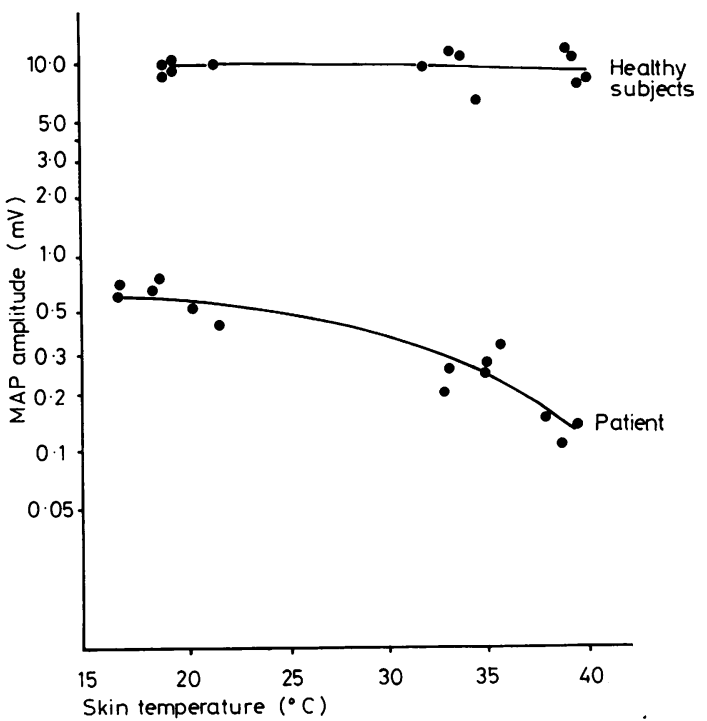

Fig. 1 Variation of amplitude of compound muscle action potential $(M A P)$ with temperature in two healthy subjects (upper trace) and in the patient (lower trace). Log scale. potential. This effect was not seen in healthy subjects (Fig. 1).

\section{POST-CONTRACTION POTENTIATION}

With rising temperature there was a decline in compound muscle action potential when resting and after potentiation, but the amounts of potentiation increased. In healthy subjects these effects of temperature were not observed (Table).

Table Effect of temperature on post-contraction potentiation

\begin{tabular}{llll}
\hline & Cold & $\begin{array}{l}\text { Room } \\
\text { temperature }\end{array}$ & Warm \\
\hline $\begin{array}{l}\text { Mean resting muscle action } \\
\text { potential (N) (mV) }\end{array}$ & 0.6 & 0.3 & 0.2 \\
$\begin{array}{l}\text { Mean post-contraction muscle } \\
\text { action potential (C) (mV) } \\
\begin{array}{c}\text { Mean post-contraction } \\
\text { potentiation }(\mathrm{C} / \mathrm{N})\end{array}\end{array}$ & 2.2 & 1.7 & 1.0 \\
\hline
\end{tabular}

STIMULATION AT 2/S AFTER REST

Decrement to about $50 \%$ of the initial muscle action potential, without recovery, occurred at all temperatures in the patient, but no decrement was observed in healthy subjects.

STIMULATION AT 2/S AFTER MAXIMAL VOLUNTARY CONTRACTION FOR 10 SECONDS

At room temperature and on warming, the initial (post-contraction) compound muscle action potential declined progressively during repetitive stimulation. On cooling, not only was the initial action potential larger than at higher temperatures but in addition repetitive stimulation resulted in a further small increase in amplitude, which reached a maximum at one second and was sustained. No effect was seen in healthy subjects.

\section{STIMULATION AT 10/S AFTER REST}

The effects of stimulation at $10 / \mathrm{s}$ are shown in Fig. 2. Ratios of successive muscle action potentials to the initial one are plotted. Serial mean values in the cold were larger than those at room temperature and the initial decrement was virtually abolished. On warming, the mean values were smaller than those at room temperature from $1.5 \mathrm{~s}$ onwards. In healthy subjects the maximum increment was $50 \%$ and occurred at room temperature.

\section{Discussion}

The effect of temperature in the Eaton-Lambert syndrome has not been described previously. In myasthenia gravis, now known to be predominantly 


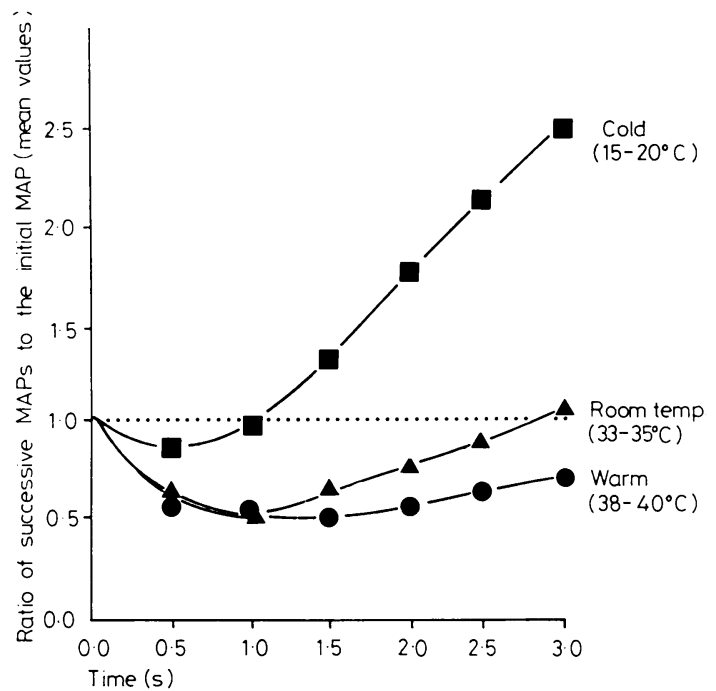

Fig. 2 Repetitive stimulation at 10/s. Mean values of the ratio of successive compound muscle action potentials (MAP) to the initial (resting) potential, at $0.5 \mathrm{~s}$ intervals. Effect of temperature in the patient. $\mathbf{-}=\operatorname{cold}\left(16-20^{\circ} \mathrm{C}\right) ; \boldsymbol{\Delta}=$ room temperature $\left(33-35^{\circ} \mathrm{C}\right)$; - $=$ warm $\left(38-40^{\circ} \mathrm{C}\right)$.

a postsynaptic disorder, neuromuscular blockade is increased with increasing temperature (Borenstein and Desmedt, 1975).

The effects of temperature on several types of presynaptic blockade have been reported. In the rat nerve-muscle preparation the blockade induced by raising the ambient magnesium concentration is enhanced by raising the bath temperature over the range $20-40^{\circ} \mathrm{C}$ (Hubbard et al., 1971). Blockade induced by botulinum toxin is temperature dependent in the same direction (Wright, 1955) as is that produced by the tick I. holocylus (Cooper and Spence, 1976). The present patient was clinically and electrophysiologically typical of the EatonLambert syndrome which has close physiological similarities to the above presynaptic disorders. Rising temperature over the range $16-40^{\circ} \mathrm{C}$ caused a decline of up to $80 \%$ in the compound muscle action potential of both resting and post-exercise muscle. Over the same range there appeared to be some increase in post-contraction potentiation but the amount of contraction was not fully standardised. Moreover, only on cooling did repetitive stimulation cause further facilitation of the postcontraction muscle action potential. The most striking effect was the decline in response to stimulation at $10 / \mathrm{s}$ observed as the temperature was raised from $16-40^{\circ} \mathrm{C}$. Rising temperature may be associated with a declining probability of acetyl- choline release (Hubbard et al., 1971), and this is one possible explanation for the effect of temperature on neuromuscular transmission in the Eaton-Lambert syndrome.

Our findings have obvious practical implications for patients. In addition, they add to the acknowledged diagnostic difficulties in this condition (Brown and Johns, 1974). The mainly proximal distribution of muscle weakness, and the small spiky motor unit potentials of decreased mean duration typically found on electromyography (Rooke et al., 1960) may lead to the misdiagnosis of myopathy. Recording at low temperatures may result in misleadingly normal amplitudes of compound action potentials while the characteristic incremental response to repetitive stimulation is best seen in the cold and may indeed be missed at higher temperatures, particularly if rates above $10 / \mathrm{s}$ are not used. The most reliable diagnostic test remains that of stimulation after voluntary contraction (Elmqvist and Lambert, 1968), since the compound muscle action potential shows a large increment at all three temperature ranges.

Our thanks are due to the patient for his cooperation and also to Dr J. Newsom Davis and Dr D. G. Small for their great help in the preparation of this report.

\section{References}

Borenstein, S., and Desmedt, J. (1975). Local cooling in myasthenia. Archives of Neurology, 32, 152-157.

Brown, J. C., and Johns, R. J. (1974). Diagnostic difficulties encountered in the myasthenic syndrome sometimes associated with carcinoma. Journal of Neurology, Neurosurgery, and Psychiatry, 37, 12141224.

Cooper, B. J., and Spence, I. (1976). Temperaturedependent inhibition of evoked acetylcholine release in tick paralysis. Nature, 263, 693-695.

Elmqvist, D., and Lambert, E. H. (1968). Detailed analysis of neuromuscular transmission in a patient with the myasthenic syndrome sometimes associated with bronchogenic carcinoma. Mayo Clinic Proceedings, 43, 689-713.

Hubbard, J. I., Jones, S. F., and Landau, E. M. (1971). The effect of temperature change upon transmitter release, facilitation and post-tetanic potentiation. Journal of Physiology (London), 216, 591-609.

Rooke, E. D., Eaton, L. M., Lambert, E. H., and Hodgson, C. H. (1960). Myasthenia and malignant intrathoracic tumor. Medical Clinics of North America, 44, 977-988.

Wright, G. P. (1955). Neurotoxins of Clostridium botulinum and Clostridium tetani. Pharmacological Reviews, 7, 413-465. 